\title{
Development of research capacity of a future social pedagogue in the face of digital technologies
}

\author{
Rysbek Maussumbayev ${ }^{1} \cdot$ Rymshash Toleubekova' $^{1}$ Karas Kaziyev² $^{2}$ \\ Axaule Baibaktina $^{3}$ - Altynshash Bekbauova ${ }^{3}$
}

Received: 12 May 2021 / Accepted: 17 January 2022 / Published online: 29 January 2022

(C) The Author(s), under exclusive licence to Springer Science+Business Media, LLC, part of Springer Nature 2022

\begin{abstract}
The aim of this article is to theoretically and practically justify the development of a future social pedagogue's research capacity in the context of digital technologies. Practical implementation of a model for building social pedagogues' research capacity within the framework of an online educational course can provide effective training of pedagogues in a digitalized educational environment and ensure a high level of pedagogical excellence. Approbation of the model was carried out on bachelor students majoring in Social Pedagogy and Self-Knowledge and taking an online Scientific Research Organization and Planning course in the Pavlodar Pedagogical University (Kazakhstan). The course was held from September to December 2020 on the Moodle learning platform, one of the most popular for the purposes of e-learning. The communication part of the course was supported by the social networking features of Facebook. In total, the educational experiment encompassed 52 students. Their thorough examination enabled the conclusion that research capacity brings proficient results in creative, innovative, communication, leadership, pedagogical, and digital activities, and thus remains an important component of pedagogical excellence. Thus, it can be stated that the integration of digital tools and platforms, along with the creation of multimedia learning content and the introduction of research methods and structured research practice into the students' education, allows for an effective research learning practice. The results of the students' end-of-course survey identified factors that had a significant influence on the effectiveness of research activities in online learning, namely the quality of the digital platform, structured research practice, active learning opportunities, pedagogical excellence, effective communication, and personalization.
\end{abstract}

Keywords Digital learning platforms $\cdot$ e-learning $\cdot$ Online course $\cdot$ Pedagogical excellence $\cdot$ Research capacity 


\section{Introduction}

The education of the 21 st century is witnessing a gradual shift of learning activities from a traditional teacher-centered approach to a more constructivist one oriented toward students. Under such conditions, knowledge is actively constructed through meaningful learning experiences gained in self-directed and personalized learning practices enabled by digital technologies and pedagogical innovations (Sailin \& Mahmor, 2018). Modern digital technologies open up excellent opportunities for ensuring constructive social interaction (Greenhow \& Askari, 2017), improving collective learning, offering more learning flexibility and personalization, and making it more student-centered (Zidoun et al., 2019). Correspondingly, their application may become a useful aid for individuals designing the educational process of the 21 st century.

In this day and age, students' learning and digital pedagogy are inextricably linked and driven by such characteristics as efficiency, quality, intensity, personalization, and adaptation. The purpose of the digital transformation of education and digital pedagogy, in particular, is to create non-standard algorithms for solving traditional pedagogical tasks as well as forming and developing an innovative learning process based on digital intelligence, big data, and distributed computing. These innovations effectively contribute to the development of individual learning trajectory, implementation of adaptive learning systems and algorithms, maintenance of digital records of students' progress, and development of dedicated systems allowing one to assess and control students' progress (with detailing and specialization of different levels) and measure the degree of development of student's necessary competencies (Toktarova \& Semenova, 2020). Modern information and communication technologies have enormous potential. The two-way communication allows each learning process participant to actively work, interact, and cooperate with others (Velichová et al., 2020). The integration of digital technologies into the learning process can support active and meaningful learning by presenting opportunities for authentic learning through exploratory experimentation or experiential learning (Sailin \& Mahmor, 2017).

In recent times, research capabilities have attracted burning interest among academics and practitioners. At the core, research capability refers to an ability to conduct good-quality research in a professional field (Caingcoy, 2020). Research is an important tool for national and global progress (Tamban \& Maningas, 2020). And the level of education of people involved in such intellectual work as well as their skills and general qualifications, play a critical role here. The public knowledge involved in technological, information, and communication systems forms the national intellectual capacity conditionally divided into realized and unrealized. As time passes, the realized capacity is converted into intellectual capital through a transfer to an intellectual product created by professionals and is recognized as part of intellectual property. The capacity that exists in an unrealized form is the body of knowledge and skills of professionals not involved in the production process. The development of this capacity is influenced by the educational system (Miethlich et al., 2020). Developments in science and technology are posing new socio-economic challenges that are becoming increasingly complex and diverse. Consequently, consciously or unconsciously, everyone is required to be more creative in dealing with the various 
rapidly evolving life problems. Higher education should foster the comprehensive development of scientific knowledge, skills, and creativity of students during the learning to develop the ability to critically analyze real-world problems and find possible creative and innovative solutions (Zainuddin et al., 2020).

Research is widely recognized as a key element of professional training for both future social pedagogues and their instructors. Yet, despite its importance, research in pedagogical education is often criticized and challenged (Murray \& Vanassche, 2019). Pedagogical training usually represents an articulated discourse about the profession of an educator with a relatively weak and adapted research base. Though, it cannot be regarded as research-based only because of the fact that future social pedagogues write an evidence-based student thesis. Instead, their whole training needs to be developed within the concept of research-based education, taking into account the course content, its research base, and the current learning models. This approach will allow future pedagogues to reflect on and be thoughtful about the demands of an ever-changing environment and adapt easily to innovative shifts in the educational system (Alvunger \& Wahlström, 2018).

An essential part of pedagogical excellence is research capacity, which is the ability to successfully achieve the goals of research activities in the learning process. Such capacity can be developed through the accumulation of research experience (Manongsong \& Panopio, 2018), which requires applying acquired knowledge and skills to produce first-grade results. Research capacity-building actions should be seen as a directed form of professional development (or learning) for pedagogues as independent practitioners and professional community members (Murray \& Vanassche, 2019). Increasing the research capacity of educators implies a change in their professional profiles, including a change in the working repertoire of knowledge that enables a person to perform prior professional tasks (Griffioen, 2020).

Improving the capacity of educators to meet the demands of educational innovation is both a goal and a motivation and is referred to as one of the most crucial success factors in the renewal of the educational system. Therefore, it is necessary to focus on educating social pedagogues in the following areas: professional ethics; learning capacity; program development capacity; research capacity; social engagement capacity; ability to provide education, science, and technology transfer services; capacity for international cooperation in higher education with an emphasis on the ability to elaborate teacher training and general education programs directed on the development of students' integrated pedagogical competence while combining theory and practice (Phunga et al., 2020).

This study aimed to theoretically and practically justify the need for the development of the research capacity of a future social pedagogue in the context of digitalization.

For this goal achievement, the following objectives are to be attained:

- determine the theoretical foundations for the development of the research capacity of a future social pedagogue in the context of e-learning;

- work out a model for developing the research capacity of a future social pedagogue within the structure of an online course; 
- test the model for developing the research capacity of a social pedagogue in an online environment;

- define the factors influencing the effectiveness of research activities of future social pedagogues in the process of e-learning.

\section{Materials and methods}

\subsection{Theoretical framework}

\subsubsection{The structure of the social pedagogue's capacity}

The nature of knowing and learning is the ground for understanding how learning communities behave and create new knowledge. To date, numerous theoretical foundations of knowledge construction and research capacity building have been created, including social learning, problem-based learning, situated learning, and knowledge management (Robinson et al., 2020). By and large, learning is a collaborative effort directed toward solving problems related to the actual design, assigning independent repetitive tasks, and creating a social environment by means of group interaction under the constructivist approach. Constructivism, in turn, is a student-oriented way of education that underlines that students construct their knowledge by linking new information with the existing one. According to constructivist learning theory, learning is defined as the creation of relationships between new knowledge and prior experience. Students meet their learning needs, achieve their learning goals, solve problems under the guidance of an educator using different resources and tools, support each other as a group (Korucu \& Atun, 2017), and hence, accumulate personal pedagogical capacity.

The problem of teacher education and training primarily concerns the relationship between professional and pedagogical competence. One of the important elements on which educators build their professional identity is their pedagogical role in the learning process. The teacher's role is never unambiguously defined but influenced by many internal and external factors. Internal factors influence the social pedagogue's perception of themselves as a participant in the learning process. In parallel, external ones incorporate attitudes and expectations about the pedagogue's role that arise from students, parents, colleagues, academic administration, and the public. Both types of factors are weighty for the teacher's professional identity. The internal factors that influence the understanding of the social pedagogue's role are created by pedagogues themselves and can be divided into two categories: educator's beliefs about what role is important and educator's expectations about their role (Makovec, 2018). In addition to the aforementioned factors, there are also individual psychological characteristics such as research orientation or preference for research, extrinsic and intrinsic motivation, research confidence or self-efficacy, and a desire for achievement and recognition, which have a substantial impact on teaching quality (Heng et al., 2020).

Pedagogical capacity is a type of competence summarizing the elements which have an integral relationship with each other, including knowledge, skills, personal 


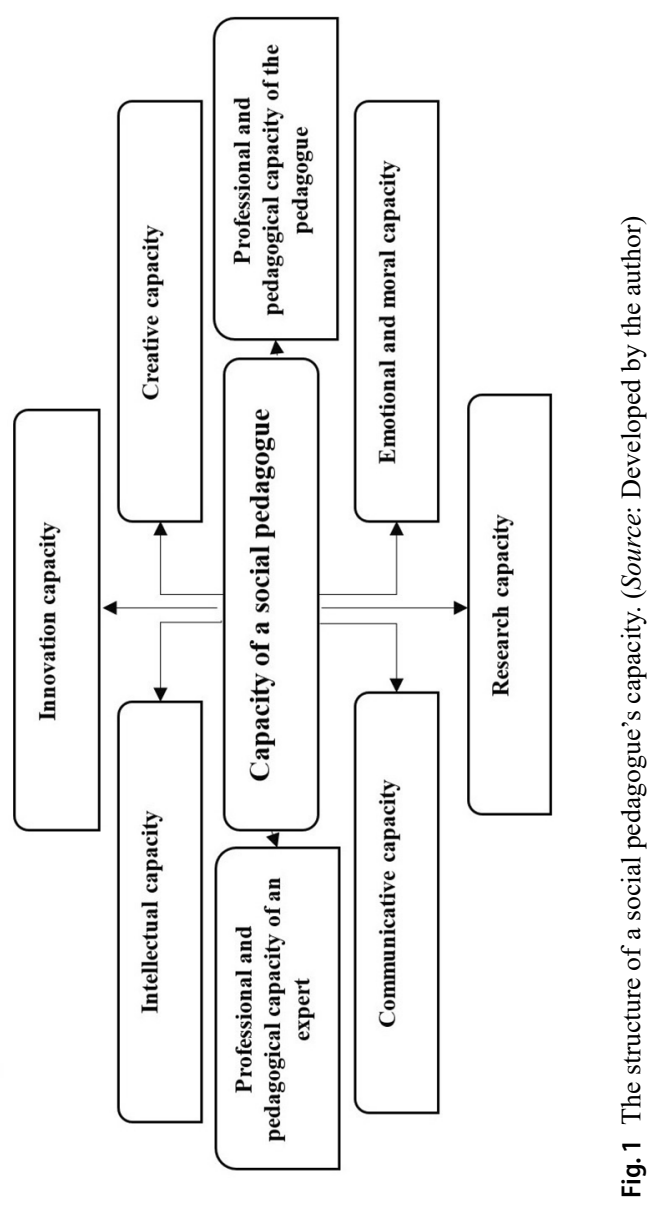


qualities, methods, manners, and qualities of a pedagogue, and constituting internal capabilities and conditions which ensure a high level of pedagogical work (Phunga et al., 2020). The category 'capacity' should be considered as a set of tools, foundations, and sources used for certain purposes. It is related to the level of the ability to perform a certain action or function. In humanities and social pedagogy, the term 'capacity' typically refers to human resources, reserves, or capabilities. Figure 1 presents the structure of the pedagogical capacity of a future social pedagogue.

The complex capacity of a social pedagogue consists of seven interrelated elements that determine the pedagogical excellence of an educator, including innovative, intellectual, creative, communicative, emotional-moral, research, and professional-pedagogical capacity. The elements of pedagogical capacity are formed and developed in synergy and interdependence.

\subsubsection{The role of digital technologies in the system of development of professional competencies of future social pedagogues}

The modern stage of socio-economic development of the world is characterized by the movement toward a digital society through the development of the digital economy, which implies the transformation of the entire system of production and service provision with the help of information and communication technologies (Toktarova \& Semenova, 2020). Digital technologies have changed the content of many common concepts, such as government, commerce, democracy, and learning, thereby providing the public with new concepts created through the prefix 'e' (Sivalingam et al., 2018). Special attention should also be paid to the problems of developing digital literacy in technical, vocational, and higher education (Narikbaeva \& Savenkov, 2016).

At the same time, the increasing penetration of internet services, and especially social media, has grammatically improved the digital literacy of people. Cloud computing, the Internet of Things, virtual reality, interactive touch screens, 3D printing, e-learning solutions, open-source mobile applications, and high-speed communications have made digital technologies interactive and user-friendly (Ahmad et al., 2020). As a result, in the 21 st century, digital technology has become a major factor in economic development. Particularly this stimulated the Republic of Kazakhstan to introduce the Digital Kazakhstan program on 12 December 2017, the central aims of which were to accelerate the development of the Republic's economy, improve the quality of life of the population in the short and long terms, and provide a development trajectory for the economy of Kazakhstan to develop digital technologies further.

The digital transformation of education systems at all levels has allowed incorporating a new teaching-learning ecosystem called e-learning. The concept of e-learning is a technology-mediated learning approach of great potential from the educational perspective (Valverde-Berrocoso et al., 2020). It is widely used by educational institutions to support the learning process and provide students with access to educational materials at any time (Selviandro \& Hasibuan, 2013). The integration of technologies into the learning process has led to the need to disseminate digital learning methods in teacher training environments. E-learning uses different technological 

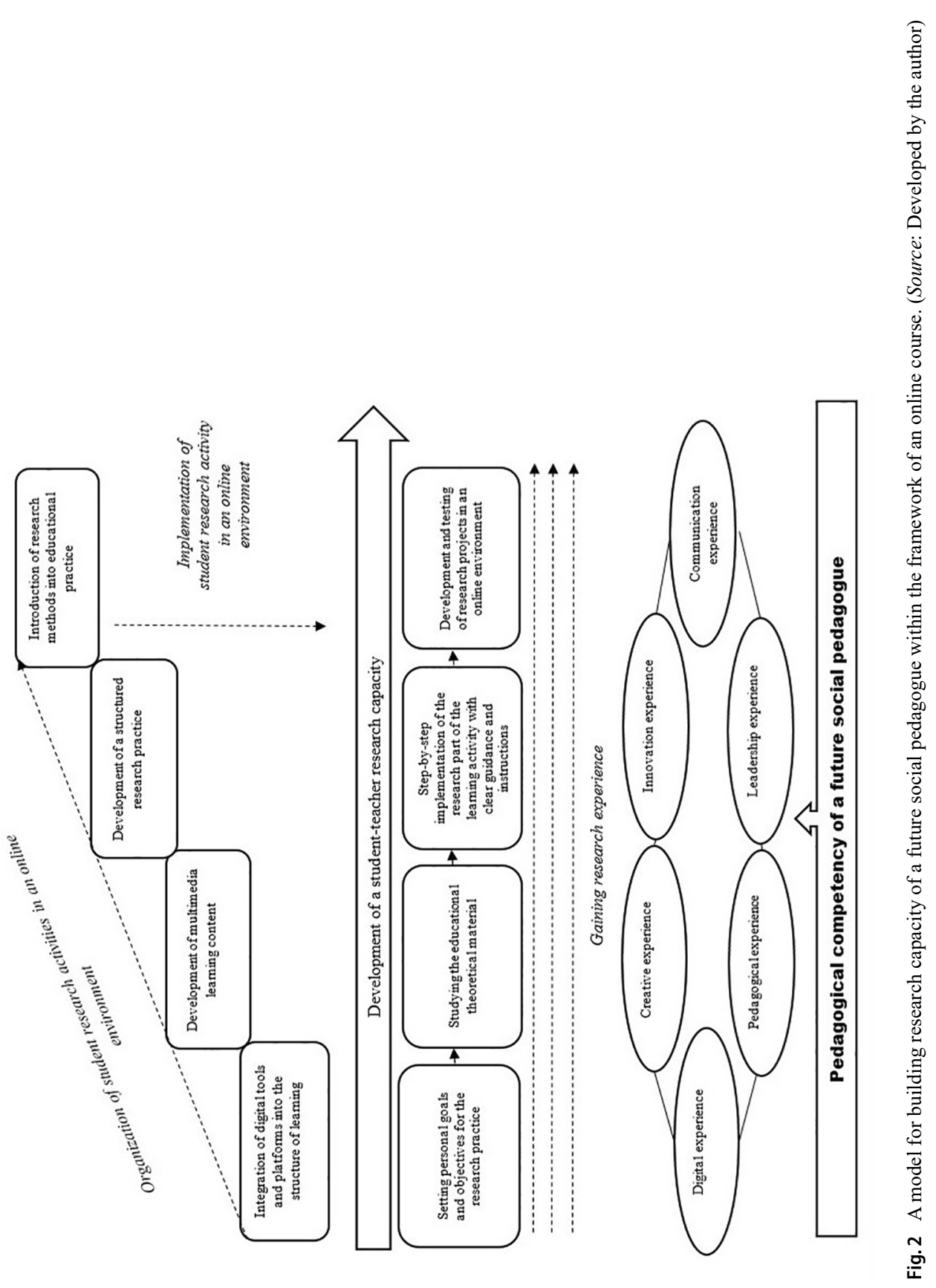
tools to access and provide information over the internet, making teaching and learning more effective by improving the quality of interaction and helping educators and students achieve educational goals. As of today, there is a wide range of e-learning tools providing students with the opportunity to create their digital environment and learn according to their personal needs (Gupta, 2019).

The development of e-learning has led to the emergence of innovative features aimed at helping educators and students in learning. The cloud-based online services segment has become extremely appealing for various educational institutions due to such useful features as geographical distribution, cost-effectiveness of automated systems, and associated open-source software (Hussein \& Hilmi, 2020). The educator in e-learning becomes a leader of collective knowledge creation supported by a learning portal based on cloud computing and artificial intelligence. This means that the educator's position is to lead a forum for collaborative learning and sharing, using the cloud as a resource provider (Hendradi et al., 2019). By strengthening the connection between students and educators, cloud-based education services make it possible to create live and interactive learning platforms, work in groups, and implement more effective and innovative teaching methods (Naveed \& Ahmad, 2019). At present, cloud computing technologies are mainly represented by money-saving services allowing high-quality training. Besides, knowledge management systems that rely on technological infrastructure are viable for continuous knowledge accumulation, processing, and transfer (Liu et al., 2020).

Currently, the main objective of pedagogical education is to train techno-educators who are capable of developing and implementing digital pedagogy. Educators should be able to integrate technology into instruction by understanding their role in technology-oriented classrooms and developing skills to use web-based technologies in practice (Dangwal \& Srivastava, 2016). Therefore, it is predicted that a new generation of pedagogical methodologies and teaching and learning approaches will focus predominantly on the individuality of students, and social media will be a central means of the personalization process. Integrating social media into the institutional structures of education is expected to create individualized and easily adaptable academic pathways toward meeting the needs of each student. By maintaining a clear structure of curricular-based learning goals and combining them with new ways of digital control of the educational process and learning experience will enable improving the quality and fruitfulness of education and, at the same time, positively influence students' motivation (Cunha et al., 2020).

\subsection{Research design and sampling}

Given the relevance of research activities in the process of training future social pedagogues, a model for building social pedagogues' research capacity within the framework of an online educational course was developed (Fig. 2).

Organizing high-quality and effective research activities for students in an e-learning format presupposed the four steps to be taken:

1) integration of digital tools and platforms into the structure of learning activities;

2) development of multimedia learning content; 
3) development of a structured research practice;

4) introduction of research methods into the student's educational activities.

In turn, students' research activities in an online environment were carried out in the following sequence of steps:

- setting personal goals and objectives of the research practice;

- studying the theoretical educational material;

- gradual implementation of the research part of the learning activity with clear guidance and instruction;

- development of research projects and their testing in the online environment;

The development of future social pedagogues' research capacity takes place in parallel with the acquisition of research experience, which is formed by first-grade results in creative, innovation, communication, leadership, pedagogical, and digital activities. Practical implementation of the model for building social pedagogues' research capacity within an online educational course is believed to assure high-level preparation of future pedagogues in the digitalized educational environment and contribute to the development of their pedagogical excellence.

Approbation of the model was carried out on the example of bachelor students majoring in Social Pedagogy and Self-Knowledge and taking the Scientific Research Organization and Planning course in the Pavlodar Pedagogical University (Kazakhstan). Overall, the experimental training enrolled 52 individuals who gave their consent for the personal data processing and survey results publication. The structure of the study group is presented in Table 1 .

The Scientific Research Organization and Planning course took place from September to December 2020 on Moodle, one of the most popular platforms for e-learning. The communication part of the course was carried out by means of the social networking features of Facebook. In order to identify the factors that exert the most significant influence on the effectiveness of research activities of future social pedagogues in e-learning, it was decided to end the course with a joint online discussion.

Experiment participants' surveys were developed and carried out using the capabilities of the Survio online platform (2021). This particular choice can be explained by the fact that the platform provides an opportunity to create questionnaires and

Table 1 The structure of the study group

\begin{tabular}{llll}
\hline Group & Number of students & Educational program & University \\
\hline SpiS-21 & 10 & 6B01810_-Social Pedagogy & Pavlodar \\
SPiS-21c & 1 & and Self-Knowledge & Peda- \\
SPiS-22 & 3 & & gogical \\
SPiS-32 & 5 & & University \\
SPiS-32c & 2 & & \\
SPiS-31 & 6 & & \\
SPiS-41 & 14 & & \\
SPiS-42 & 11 & & \\
Total: 52 & & & \\
\hline
\end{tabular}


share them with other people via Facebook. The creation of forms to be filled was done using available templates from the Survio database.

\subsection{Research limitations}

Since the educational experiment was carried out within the Scientific Research Organization and Planning course, the thematic purpose of which was to instill research skills in future social pedagogues, the proposed model was limited to the course concept. In view of this, the effectiveness of the model for developing students' research capacity in online learning should be further explored within the framework of a comprehensive teacher development program.

\section{Results}

At the end of the educational course, students were asked to complete a specially prepared questionnaire to assess the individual performance of the participants in their research activity and the factors that affect the quality of the course incorporating a comprehensive model for building research capacity in online settings (Table 2).

Through an online discussion on Facebook and student feedback on e-learning experience, the course moderators identified the factors that influence the effectiveness of research activities in the digital environment. Hence, it was unveiled that the top-important determinants in developing future social pedagogues' research capacity and acquiring pedagogical excellence in an e-learning environment are the quality of the digital platform, structured research practices, active learning opportunities, and pedagogical excellence, effective communication, and personalization (Fig. 3).

Table 2 Factors impacting the quality of the course that incorporated a comprehensive research capacity building model in the digital setting. (Source: Developed by the author)

\begin{tabular}{|c|c|c|c|c|}
\hline \multirow[t]{2}{*}{ Factor } & \multicolumn{4}{|c|}{ Impact rating ( $1-5$ points $)$} \\
\hline & $\begin{array}{l}\text { Minimum } \\
\text { impact } \\
(1-2)\end{array}$ & $\begin{array}{l}\text { Me- } \\
\text { dium } \\
\text { impact } \\
(2-3)\end{array}$ & $\begin{array}{l}\text { High } \\
\text { impact } \\
(3-4)\end{array}$ & $\begin{array}{l}\text { Maxi- } \\
\text { mum } \\
\text { impact } \\
(4-5)\end{array}$ \\
\hline Training using modern digital tools and platforms & & & $25 \%$ & $75 \%$ \\
\hline E-learning platform quality & & & $17 \%$ & $83 \%$ \\
\hline Multimedia learning content & $2 \%$ & $5 \%$ & $47 \%$ & $46 \%$ \\
\hline Structured research practice & & $10 \%$ & $75 \%$ & $15 \%$ \\
\hline Implementation of research methods in educational activities & $3 \%$ & $7 \%$ & $23 \%$ & $67 \%$ \\
\hline $\begin{array}{l}\text { Clear guidance and instructions on achieving research } \\
\text { objectives }\end{array}$ & & & $11 \%$ & $89 \%$ \\
\hline Testing of research projects in an online environment & & $16 \%$ & $56 \%$ & $23 \%$ \\
\hline Social presence and cooperation & & $4 \%$ & $7 \%$ & $89 \%$ \\
\hline Active learning & & & $26 \%$ & $74 \%$ \\
\hline Effective communication & & & $9 \%$ & $91 \%$ \\
\hline Personalized learning & & & $4 \%$ & $96 \%$ \\
\hline
\end{tabular}




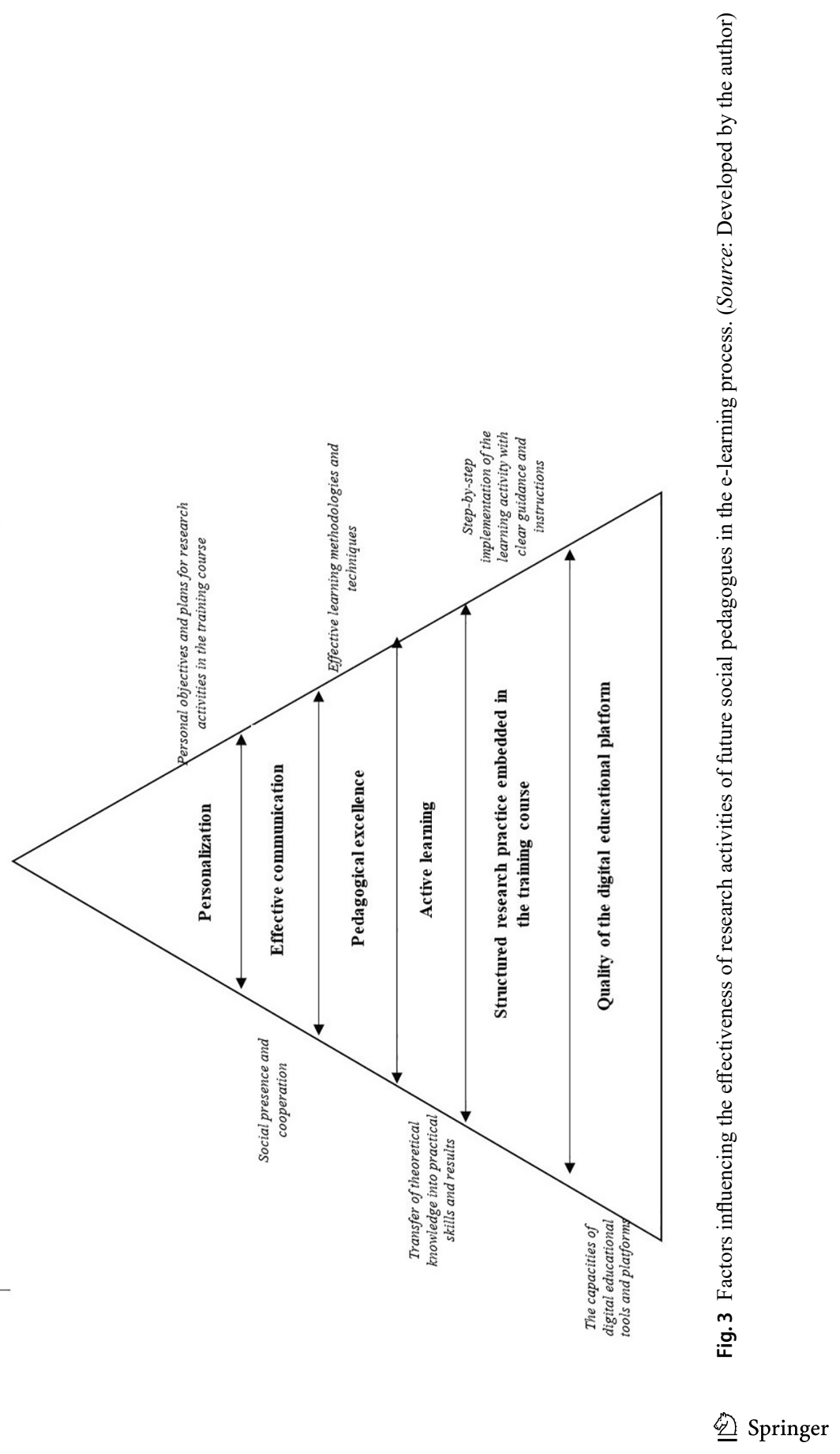


The quality of a digital platform is determined by the ease of its use, the effectiveness of educational content delivery, support permanence and availability, and flexibility to connect students to mixed/synchronous modalities. Following the experiment results, most students $(82 \%)$ confirmed that the digital learning interactions on Moodle increased their engagement, motivation, and persistence toward their learning goals, as well as had an influence on the development and retention of their digital literacy skills $(87 \%)$. The ease of the online platform and the set of proposed digital tools was proved to positively affect respondents' perception of learning activities (73\%) and level of intrinsic satisfaction and learning motivation (85\%). Moreover, it was revealed that learning activities in a digital learning environment allowed students to reduce cognitive load and focus on real learning tasks, which was confirmed by $82 \%$ of the surveyed.

Structured research practice is defined by the step-by-step implementation of learning activities with clear guidance and instruction embedded in the learning content (video, audio, textual instructions, etc.). Professional pedagogical education should have direct linkages to the everyday practice of teaching, a fundamental element of which is research. In this respect, $85 \%$ of students indicated that clear models of research concepts as well as strategies and ideas presented in the form of media guidelines and instructions allow for a comprehensive understanding of research work in the practice of the modern social pedagogue.

Active learning is based on the mechanisms of active interaction with content and student-teacher cooperation. It opens broad opportunities for demonstrating key research competencies in the student's practice. Furthermore, as evidenced by $94 \%$ of respondents, active interaction strategies increase research persistence and productivity. The Scientific Research Organization and Planning course provided students with opportunities to apply theoretical knowledge in practice making the learning process more meaningful. In addition, students had the possibility to practice teamwork skills as researchers and organizers.

Pedagogical excellence is determined by the capacity for sustained research and educational activities under the curriculum, work with feedbacks, and objective assessment of the results. Thus, for the learning to be productive, it should be grounded on the pursuit of professional excellence through research practice, fair assessment, and comments provision. For $79 \%$ of students, opportunities for conscious practice or individual training outlined personal vectors for pedagogical excellence. For $73 \%$ of them, the instructors' innovative and creative approach had a significant influence on the uptake of pedagogical skills and engaged in the search for effective tools for learning interaction. Finally, $89 \%$ of respondents indicated that quality and prompt feedback, which supports student reflection and provides an objective assessment of their pedagogical skills' mastery, is an important characteristic of productive learning.

Effective communication is crucial for the achievement of quality research outcomes. It is the connection with an expert/educator, collaboration with colleagues, and digital opportunities that sustain social presence. However, the conducted investigation showed that professional education in the field of social pedagogy becomes even more successful in a digital environment. Online conditions that promote peer learning and interaction are associated with higher levels of student comfort (95\%), 
learning flexibility (79\%), and connectivity (98\%). And $93 \%$ of students confirmed that instructor-led learning is an essential and effective e-learning component.

As for the personalization in a learning practice, it allows students to activate their experience and knowledge, implement research activities according to personally set goals and objectives, and rely on individualized support from educators. The present study unveiled that personalization through e-learning platforms offers substantial opportunities for professional development consistent with the needs and preferences of a contemporary student (91\%). In addition, personalization incorporated into the concept of an educational course was confirmed to focus on students' personal aims, allowing for a personalized pedagogical development and research skills improvement plan $(89 \%)$.

Table 3 below explicates the results of students' research activity progress selfassessment that was proposed for them to perform after the experiment ended. For this, respondents were asked to rank their digital, creative, innovation, communication, leadership, and pedagogical experiences.

\section{Discussion}

Research capacity developed through the accumulation of research experience is of great value for pedagogical excellence. As evidenced by the present study, investigation-directed activities incorporated into the educational course have a significant effect on the integrated capacity of a social pedagogue, which consists of seven interrelated elements: innovative, intellectual, creative, communicative, emotional and moral, research, and professor-pedagogical. All of these elements are forming and developing in synergy and interrelation. Even research capacity building of an educator occurs in parallel with the acquisition of research experience, which acts upon creative, innovative, communication, leadership, pedagogical, and digital activities.

There are many approaches to pedagogical education, one of which is based on the notion that the knowledge base of the curriculum is dynamic and that studentteachers are active knowledge processors. Research-based thinking is seen as a linking factor in this process. Identifying pedagogical elements and asking pedagogically relevant questions in learning situations are only few of the paramount skills a future practitioner needs. Key factors determining research-based pedagogical education

Table 3 Evaluation of personal progress in research activity in the e-learning process. (Source: Developed by the author)

\begin{tabular}{lllll}
\hline Research capacity & \multicolumn{4}{l}{ Evaluation of personal progress (1-5) } \\
\cline { 2 - 4 } & $\begin{array}{l}\text { Minimum effect } \\
(1-2)\end{array}$ & $\begin{array}{l}\text { Medium effect } \\
(2-3)\end{array}$ & $\begin{array}{l}\text { High effect } \\
(3-4)\end{array}$ & $\begin{array}{l}\text { Maximum effect } \\
(4-5)\end{array}$ \\
\hline Digital experience & $2 \%$ & $23 \%$ & $75 \%$ \\
Creative experience & & $14 \%$ & $86 \%$ \\
Innovation experience & & $9 \%$ & $91 \%$ \\
Communication experience & & $2 \%$ & $98 \%$ \\
Leadership experience & & $14 \%$ & $86 \%$ \\
Pedagogical experience & & $4 \%$ & $96 \%$ \\
\hline
\end{tabular}


incorporate the following points. First of all, the curriculum is structured according to the systemic educational structure. Secondly, all learning and teaching are researchbased. Thirdly, activities are organized in such a way as to give students the opportunity to practice argumentation, decision making, and justification when inquiring and solving pedagogical problems. Lastly, students learn different research skills during their studies (Toom et al., 2008).

Concurrently, research-based learning is a multi-faceted concept that tightly links research and teaching. Accordingly, a research-based teaching practice should ensure that the obtained research findings influence the curriculum, teaching and learning methods are grounded on the research, and educators benefit from research elements while teaching (Yulhendri et al., 2018). Research-based education deals with analysis, synthesis, and evaluation activities and enables students and educators to improve the absorption and application of knowledge. More and more scholars indicate that research is an essential means of enhancing learning quality, and research-based learning is conducted under constructivism covering four aspects: learning which constructs students' understanding, learning through developing prior knowledge, learning which involves social interaction process, and meaningful learning, which is achieved through real-world experience (Susiani et al., 2017).

Current generations of students have grown up with information technology, and this influences learning strategies dramatically as technology is more and more often perceived as a fundamental element of academic success. Students note that technologies such as smartphones, social media, and educational platforms are critical social pedagogical tools for solving research problems ( $\mathrm{Ma} \& \mathrm{Au}, 2014$ ).

Pirozhkova (2021) argues that research-based learning is the process of acquiring knowledge through analysis, experiments, and data interpretation through scientific analysis methods. The results of her study on the impact of a research-oriented educational approach at the Ural State University of Economics confirms that the integration of research into teaching various disciplines can bring the following advantages:

- for students - development of critical professional and general competencies and a better understanding of science and professional subjects motivating them for successful learning.

- for faculty - better students' performance and involvement in classroom work;

- for the university - publication of students' works in journals and conference proceedings (Pirozhkova, 2021).

A research-based approach to teaching may be more successful than the traditional when it comes to linking theory and practice using real-life case studies and contemporary social issues. The development of students' research capacity occurs in the process of active educational activity together with the mastery of reflective knowledge and critical thinking to build their personal vision of research problems. Research-based teaching should address several aspects such as research design, data collection, practical research, and interpretation of results. It should focus on actual world challenges to put students in a situation where they not only apply scientific methods but also increase their commitment and participation in the process (Espinoza-Figueroa et al., 2021). 
Affiliation of students with a project research team can increase student motivation to participate in online learning activities by providing frequent, meaningful, and motivating interactions to achieve shared results in a virtual space. A study conducted among students of the Danish problem-Based Learning University during the adaptation to educational conditions caused by COVID-19 argues that effective online work in project research teams is a skill to be practiced during the learning process. Students described group work on digital research projects as the most positive aspect of interactive learning. According to researchers, universities should inspire students to use social collaboration tools such as MS Teams and Zoom because they provide good platforms for effective collaboration in small groups helping to counter isolation and increase motivation to interact with online material due to mutual accountability (Haslam et al., 2021).

It is widely recognized that educators represent one of the primary levers of an educational institution's research capacity improvement (Shehzad et al., 2014), while university policies, practices, and resources significantly affect researchers' productivity (Huenneke et al., 2017). Since learning plays a major role in skill development, teacher education curricula should cover the latest topics to meet the requirements of the new generation of educators. Correspondingly, this requires developing new guidelines that incorporate innovative approaches such as blended learning, flipped learning, and e-learning. Although many teacher education institutions of this day lack the necessary infrastructure and technical support, management should not give up on finding ways to encourage the integration of new technological tools into the curriculum to meet the demands of 21st -century students (Gupta, 2019). At the same time, incorporating digital pedagogy into teacher education programs should be done after ensuring that technological solutions are adequate to the new approaches toward learning and instill a positive attitude toward their adoption. Such a move would help future social pedagogues learn innovative teaching strategies and thus build their confidence in digital pedagogy as part of their future pedagogical practice (Sailin \& Mahmor, 2017). Effective implementation of digital pedagogy depends on students' acceptance of e-learning tools which are in turn influenced by technology (easeof-use, speed availability, and service delivery), organization (learning support), environment (user attitudes), and impact-related factors (learning experience, skill development, performance, degree of engagement) (Eze et al., 2020). The dominant factor that requires attention in understanding the effectiveness of e-learning implementation in higher education is the organizational aspect, which manifests itself in creating a working culture and establishing policies mandatory for the academic community when conducting e-learning (Priatna et al., 2020). These factors are also worth considering when designing programs for the integration of technological tools and platforms into the research capacity building strategy of social pedagogues.

The results of this study confirmed that high-quality and productive research activities of future social pedagogues in e-learning format are achieved through the integration of digital tools and platforms into learning, the development of multimedia learning content, the implementation of structured research practices, and the provision of active learning opportunities. The steps of research capacity building of future social pedagogues in the online environment are as follows: 
- $\quad$ setting personal goals and objectives of the research practice;

- studying the theoretical educational material;

- gradual implementation of the research part of the learning activity with clear guidance and instruction;

- development of research projects and their testing in the online environment;

\section{Conclusions}

Implementing the proposed model for social pedagogues' research capacity building within the framework of an e-learning course can ensure effective preparation of future teachers in a digital setting and result in a high level of their pedagogical excellence. Most of the students confirmed that digital opportunities for interaction provided by Moodle e-learning increased their level of engagement, motivation, and persistence in achieving educational goals, as well as influenced the development and consolidation of digital and media literacy skills. The ease of using the online platform and digital tools had a positive influence on students' perception of learning, their level of intrinsic satisfaction, and learning motivation. By reducing the level of cognitive load, learning activities in a digital environment allowed students to focus on real learning tasks. Clear research concepts, strategies, and ideas presented in the form of media guidelines and instructions allowed forming a comprehensive understanding of research work in the practice of a modern social pedagogue. Active interaction strategies facilitated research persistence and productivity. Instructors' innovative and creative approach had a favorable effect on the uptake of pedagogical skills and engaged participants in the search for effective tools for learning interactions.

Students' assessment of the factors affecting the quality of a comprehensive research capacity building model allowed the inference the most influential of them are learning with modern digital tools and platforms $(75 \%)$, e-learning platform quality (83\%), clear guidance and instructions on achieving research goals $(89 \%)$, social presence and collaboration (89\%), active learning (74\%), effective communication (91\%), and personalization (96\%).

In general, students' perception of the learning practices based on the integration of digital tools and research approaches was positive. At the end of the educational experiment, most respondents confirmed the educational value of the course. This implies that the proposed model for research capacity building in a digital educational environment is worth to be implemented within teacher education. The prospects for future research are seen in studying the effectiveness of the proposed model in the structure of comprehensive programs aiming to prepare future pedagogues.

Acknowledgements Not applicable.

Authors' contributions All authors contributed to the study conception and design. Material preparation, data collection and analysis were performed by Rysbek Maussumbayev, Rymshash Toleubekova, Karas Kaziyev. The first draft of the manuscript was written by Axaule Baibaktina, Altynshash Bekbauova and 
all authors commented on previous versions of the manuscript. All authors read and approved the final manuscript.

Funding This research did not receive any specific grant from funding agencies in the public, commercial, or not-for-profit sectors.

Availability of data and material Data will be available on request.

Code Availability Not applicable.

\section{Declarations}

Conflict of interest The authors declare that they have no conflict of interests.

Ethics approval The authors declare that the work is written with due consideration of ethical standards. The study was conducted in accordance with the ethical principles approved by the Human Experiments Ethics Committee of L.N. Gumilyov Eurasian National University (Protocol No 4 of 12.08.2020).

Consent to participate All the participants gave their written informed consent to the participation in the experiment.

Consent for publication All the participants gave their consent to the publication of the experimentresults.

\section{References}

Ahmad, N., Hoda, N., \& Alahmari, F. (2020). Developing a cloud-based mobile learning adoption model to promote sustainable education. Sustainability, 12, 3126. https://doi.org/10.3390/su12083126

Alvunger, D., \& Wahlström, N. (2018). Research-based teacher education? Exploring the meaning potentials of Swedish teacher education. Teachers and Teaching, 24(4), 332-349. https://doi.org/10.1080 /13540602.2017.1403315

Caingcoy, M. (2020). Research capability of teachers: Its correlates, determinants and implications for continuing professional development. Journal of World Englishes and Educational Practices, 2(5), 1-11. https://doi.org/10.2139/ssrn.3631867

Cunha, M. N., Chuchu, T., \& Maziriri, E. T. (2020). Threats, challenges, and opportunities for open universities and massive online open courses in the digital revolution. International Journal of Emerging Technologies in Learning, 15(12), 191-204. https://doi.org/10.3991/ijet.v15i12.13435

Dangwal, K., \& Srivastava, S. (2016). Digital pedagogy in teacher education. International Journal of Information Science and Computing, 3(2), 67-72. https://doi.org/10.5958/2454-9533.2016.00008.9

Espinoza-Figueroa, F., Vanneste, D., Alvarado-Vanegas, B., Farfán-Pacheco, K., \& Rodriguez-Giron, S. (2021). Research-based learning (RBL): Added-value in tourism education. Journal of Hospitality, Leisure, Sport \& Tourism Education, 28, 100312. https://doi.org/10.1016/j.jhlste.2021.100312

Eze, S., Chinedu-Eze, V., Okike, C., \& Bello, A. (2020). Factors influencing the use of e-learning facilities by students in a private Higher Education Institution (HEI) in a developing economy. Humanities and Social Sciences Communications, 7, 133. https://doi.org/10.1057/s41599-020-00624-6

Greenhow, C., \& Askari, E. (2017). Learning and teaching with social network sites: A decade of research in K-12 related education. Education and Information Technologies, 22(2), 623-645. https://doi. org/10.1007/s10639-015-9446-9

Griffioen, D. (2020). Building research capacity in new universities during times of academic drift: lecturers professional profiles. Higher Education Policy, 33(2), 347-366. https://doi.org/10.1057/ s41307-018-0091-y

Gupta, D. (2019). Capacity building of teacher educators for e-learning tools: An experimental study. Indian Journal of Educational Technology, 1(2), 1-13. https://doi.org/10.13140/RG.2.2.26525.87524 
Haslam, C. R., Madsen, S., \& Nielsen, J. A. (2021). Problem based learning during the COVID 19 pandemic. Can project groups save the day? Communications of the Association for Information Systems, 48, 161-168. https://doi.org/10.17705/1CAIS.04821

Hendradi, P., Khanapi, M., \& Mahfuzah, S. M. (2019). Cloud computing-based e-learning system architecture in education 4.0. Journal of Physics: Conference Series, 1196(1), 012038. https://doi. org/10.1088/1742-6596/1196/1/012038

Heng, K., Hamid, M. O., \& Khan, A. (2020). Factors influencing academics' research engagement and productivity: A developing countries perspective. Issues in Educational Research, 30(3), 965-987

Huenneke, L. F., Stearns, D. M., Martinez, J. D., \& Laurila, K. (2017). Key strategies for building research capacity of university faculty members. Innovative Higher Education, 42(5), 421-435. https://doi. org/10.1007/s10755-017-9394-y

Hussein, L. A., \& Hilmi, M. F. (2020). Cloud computing based e-learning in Malaysian universities. International Journal of Emerging Technologies in Learning, 15(8), 4-21. https://doi.org/10.3991/ijet. v15i08.11798

Korucu, A. T., \& Atun, H. (2017). Use of social media in online learning. In Handbook of Research on Innovative Pedagogies and Technologies for Online Learning in Higher Education (pp. 1-18). IGI Global. https://doi.org/10.4018/978-1-5225-1851-8.ch001

Liu, Z. Q., Dorozhkin, E., Davydova, N., \& Sadovnikova, N. (2020). Effectiveness of the partial implementation of a cloud-based knowledge management system. International Journal of Emerging Technologies in Learning, 15(13), 155-171. https://doi.org/10.3991/ijet.v15i13.14919\%0d

Ma, C., \& Au, N. (2014). Social media and learning enhancement among Chinese hospitality and tourism students: A case study on the utilization of Tencent QQ. Journal of Teaching in Travel \& Tourism, 14(3), 217-239. https://doi.org/10.1080/15313220.2014.932483

Makovec, D. (2018). The teacher's role and professional development. International Journal of Cognitive Research in Science, Engineering and Education, 6(2), 33. https://doi.org/10.5937/ijcrsee1802033M

Manongsong, M. J. G., \& Panopio, E. (2018). Dentistry faculty members' research competencies and attitude towards research engagement. Asia Pacific Journal of Education, Arts and Sciences, 5(3), 13-19

Miethlich, B., Kvitka, S., Ermakova, M., Bozhko, L., Dvoryankin, O., Shemshurina, S., \& Kalyakina, I. (2020). Correlation of educational level, labor potential and digital economy development in Slovakian, Ukrainian and Russian experience. TEM Journal, 9(4), 1597. https://doi.org/10.18421/ TEM94-35

Murray, J., \& Vanassche, E. (2019). Research capacity building in and on teacher education: developing practice and learning. Nordisk Tidsskrift for Utdanning Og Praksis, 13(2), 114-129. https://doi. org/10.23865/up.v13.1975

Narikbaeva, L. M., \& Savenkov, A. I. (2016). Pedagogical system of students vocational ability development. International Journal of Environmental and Science Education, 11(9), 3013-3024. https://doi. org/10.12973/ijese.2016.732a

Naveed, Q. N., \& Ahmad, N. (2019). Critical success factors (CSFs) for cloud-based e-learning. International Journal of Emerging Technologies in Learning, 14(1), 140-149. https://doi.org/10.3991/ijet. v14i01.9170

Phunga, T. L., Leb, Q. T., \& Buic, T. T. (2020). Improving Teaching capacity for teachers of social sciences before requesting the innovation of the general education program. International Journal of Innovation, Creativity and Change, 11(3), 527-541

Pirozhkova, I. (2021). Higher education for sustainable development: Research-based learning (the case of the Ural State University of Economics). In E3S Web of Conferences (Vol. 296, p. 08028). EDP Sciences. https://oi.org/10.1051/e3sconf/202129608028

Priatna, T., Maylawati, D. S., Sugilar, H., \& Ramdhani, M. A. (2020). Key success factors of e-learning implementation in higher education. International Journal of Emerging Technologies in Learning, 15(17), 101-114. https://doi.org/10.3991/ijet.v15i17.14293

Robinson, H., Kilgore, W., \& Bozkurt, A. (2020). Learning communities: Theory and practice of leveraging social media for learning. In G. Durak \& S. Çankaya (Eds.), Managing and Designing Online Courses in Ubiquitous Learning Environments (pp. 72-91). IGI Global. https://doi.org/10.4018/9781-5225-9779-7.ch004

Sailin, S. N., \& Mahmor, N. A. (2017). Create-share-collaborate: An instructional strategy for developing student teacher's critical thinking. In 1st Inspirational Scholar Symposium Proceedings (pp. 66-81). Universiti Utara Malaysia 
Sailin, S., \& Mahmor, N. (2018). Improving student teachers' digital pedagogy through meaningful learning activities. Malaysian Journal of Learning and Instruction, 15(2), 143-173. https://doi. org/10.32890/mjli2018.15.2.6

Selviandro, N., \& Hasibuan, Z. A. (2013). Cloud-based e-learning: A proposed model and benefits by using e-learning based on cloud computing for educational institution. In Information and Communication Technology-EurAsia Conference (pp. 192-201). Springer. https://doi. org/10.1007/978-3-642-36818-9 20

Shehzad, U., Fareed, Z., Zulfiqar, B., Shahzad, F., \& Latif, H. S. (2014). The impact of intellectual capital on the performance of universities. European Journal of Contemporary Education, 10, 273-280. https://doi.org/10.13187/ejced.2014.10.273

Sivalingam, D. R., Balachandar, R., \& Ajith, P. (2018). E-Learning approach in teacher education. Journal of Applied and Advanced Research, 3(1), 14-16. https://doi.org/10.21839/jaar.2018.v3is1.159

Susiani, T., Salimi, M., \& Hidayah, R. (2017). Research Based Learning (RBL): How to improve critical thinking skills? SHS Web of Conferences, 42, 00042. https://doi.org/10.1051/shsconf/20184200042

Survio online platform (2021). Official web site. https://www.survio.com/

Tamban, V. E., \& Maningas, O. B. (2020). Research capability of public school teachers: A basis for research capability enhancement program. PEOPLE: International Journal of Social Sciences, 6(1), 222-235. https://doi.org/10.20319/pijss.2020.61.222235

Toktarova, V., \& Semenova, D. (2020). Digital pedagogy: analysis, requirements and experience of implementation. Journal of Physics: Conference Series, 1691, 012112. https://doi. org/10.1088/1742-6596/1691/1/012112

Toom, A., Krokfors, L., Kynäslahti, H., Stenberg, K., Maaranen, K., Jyrhämä, R. ... Kansane, P. (2008). Exploring the essential characteristics of research-based teacher education from the viewpoint of teacher educators. In B. Åstrand, E. Eisenschmidt, B. Hudson, M. Lampere, \& P. Zgaga (Eds.), Proceedings of Second Annual Teacher Education Policy in Europe Network (TEPE) Conference: Mapping the Landscape and Looking to the Future (pp. 166-179)

Valverde-Berrocoso, J., Garrido-Arroyo, M. D. C., Burgos-Videla, C., \& Morales-Cevallos, M. B. (2020). Trends in educational research about e-learning: A systematic literature review (2009-2018). Sustainability, 12(12), 5153. https://doi.org/10.3390/su12125153

Velichová, L., Orbánová, D., \& Kúbeková, A. (2020). The COVID-19 pandemic: Unique opportunity to develop online learning. TEM Journal, 9(4), 1633-1639. https://doi.org/10.18421/TEM94?40

Yulhendri, Y., Syofyan, E., \& Afridona, S. (2018). The development of research-based learning model and journal as for graduate students' scientific publication of M.Pd.E on economic. International Journal of Scientific and Research Publications, 8(5), 500-505. https://doi.org/10.29322/IJSRP.8.5.2018. p7764

Zainuddin, S., Dewantara, D., Mahtari, S., Nur, M., Yuanita, L., \& Sunarti, T. (2020). The correlation of scientific knowledge-science process skills and scientific creativity in creative responsibility based learning. International Journal of Instruction, 13(3), 307-316. https://doi.org/10.29333/ iji.2020.13321a

Zidoun, Y., Dehbi, R., Talea, M., \& Arroum, F. Z. A. (2019). Designing a theoretical integration framework for mobile learning. International Journal of Interactive Mobile Technologies, 13(12), 152-170. https://doi.org/10.3991/ijim.v13i12.10841

Publisher's Note Springer Nature remains neutral with regard to jurisdictional claims in published maps and institutional affiliations.

\section{Authors and Affiliations}

\section{Rysbek Maussumbayev' ${ }^{1}$ Rymshash Toleubekova' ${ }^{1}$ Karas Kaziyev $^{2}$. Axaule Baibaktina $^{3} \cdot$ Altynshash Bekbauova ${ }^{3}$}

Rysbek Maussumbayev

rymaussumbayev@rambler.ru; Rysbek06051990@mail.ru 
1 Department of Social Pedagogy and Self-knowledge, L.N. Gumilyov Eurasian National University, Nur-Sultan, Kazakhstan

2 Department of Psychology and Special Education, Kh. Dosmukhamedov Atyrau University, Atyrau, Kazakhstan

3 Department of Computer Science and Information Technology, Aktobe Regional University named after K. Zhubanov, Aktobe, Kazakhstan 